\title{
Influence of Campylobacter fetus subsp. fetus on ram sperm cell quality
}

\author{
Tidhar Zan Bar, Ronen Yehuda, Tomer Hacham, Sigal Krupnik \\ and Benjamin Bartoov
}

Correspondence

Tidhar Zan Bar

tidharz@gmail.com

Received 6 February 2008

Accepted 20 May 2008

\author{
Male Fertility Laboratory, The Mina and Everard Goodman Faculty of Life Sciences, Bar-llan \\ University, Ramat-Gan 52900, Israel
}

\begin{abstract}
Campylobacter fetus subsp. fetus infection can occur in female sheep, causing infertility or abortion. Despite extensive research on the effect of these bacteria on female fertility, little research has been done on the influence of $C$. fetus subsp. fetus on the male factor. Our objective was to examine the influence of $C$. fetus subsp. fetus on ram sperm. Motility index, percentage of live spermatozoa, mean $\alpha$ t value (an indication of the chromatin stability of the sperm cell) and percentage of sperm cells expressing the FAS receptor were measured in sperm incubated in the presence or absence of C. fetus subsp. fetus. The motility index and viability of sperm incubated with the bacteria were lower than those of untreated sperm samples after $5 \mathrm{~h}$. In bacteriaincubated sperm cells, the percentage expressing FAS receptor was already significantly elevated at $15 \mathrm{~min}$. Bacteria-incubated sperm showed a greater prevalence of morphological damage. The bacteria were attached to tail and acrosome regions, and the sperm damage was concentrated in both the motility and chromatin regions. Bacteria-infected sperm cells showed a decrease in motility, increase in early acrosome reaction and chromatin damage. Similar effects were induced by incubation of the sperm with supernatants from C. fetus subsp. fetus cultures. Thus this study demonstrates that $C$. fetus subsp. fetus has a detrimental effect on the quality of ram sperm.
\end{abstract}

\section{INTRODUCTION}

Campylobacter fetus is a microaerophilic Gram-negative bacterium and a recognized veterinary and human pathogen (Garcia et al., 1983; Penner, 1988). This bacterium is divided into two closely related subspecies, Campylobacter fetus subsp. venerealis and Campylobacter fetus subsp. fetus, the latter of which is the main focus of this study. C. fetus subsp. fetus is associated with sporadic epizootic abortion in cattle and sheep (Brooks et al., 2001; Grogono-Thomas et al., 2000; Schulze et al., 2006; van Bergen et al., 2006). In Denmark, it has been reported that more than $60 \%$ of fetal loss in sheep is associated with $C$. fetus subsp. fetus infection (Agerholm et al., 2006). Similarly, in New Zealand, C. fetus subsp. fetus is the leading cause of diagnosed abortions in sheep (Mannering et al., 2006). Marked tropism for the placenta, exhibited by C. fetus subsp. fetus, was suggested to be the main cause of these abortions (Garcia et al., 1983; Steinkraus \& Wright, 1994).

In humans, C. fetus subsp. fetus has been reported to be an aetiologic agent in human abortions in general (Hood \& Todd, 1960), and of septic abortion with intact fetal membranes in particular (Steinkraus \& Wright, 1994). To the best of our knowledge, no association between infection by $C$. fetus subsp. fetus and male fertility potential has been reported. Therefore, the aim of this study was to determine the possible effect of infection by $C$. fetus subsp. fetus on sperm quality and fertility potential in rams.

We show here that incubation of ram sperm with $C$. fetus subsp. fetus or with bacterial supernatant from C. fetus subsp. fetus cultures causes defects in the sperm that were previously associated with decreased sperm quality and viability.

\section{METHODS}

All animals in this study were handled under the supervision of and according to the guidelines of the Institutional Animal Care and Use Committee (IACUC) of Bar-Ilan University, Ramat-Gan, Israel.

Sperm and bacteria preparation. Using a sterile artificial vagina, ram semen was collected from Assaf breed rams after male stimulation by a rutted female. The sample was then washed twice and diluted in Ringer's phosphate medium with glucose ( $\mathrm{pH} 5$ ).

Bacterial cultures of C. fetus subsp. fetus were a kind gift from Dr M. Bernstein of the Department of Bacteriology, Israeli Veterinary Institute in Beit Dagan, Israel. Three strains of isolated bacteria from aborted sheep fetus were obtained. Bacteria were maintained on blood agar plates under anaerobic conditions (Lancaster \& Simon, 2002).

Before each experiment, the bacteria were transferred to grow on trypticase soy agar with $5 \%$ DSB plates (Novamed) for 2 days at $37^{\circ} \mathrm{C}$. After that, the bacteria were harvested and transferred to the medium (suspension). 
Other bacteria, including Escherichia coli and Erwinia amylovora, were cultured in the same media.

Using spectrophotometry, we found that a $0.1 \mathrm{OD}_{660}$ bacterial suspension equalled a bacterial concentration of $27 \times 10^{8} \mathrm{ml}^{-1}$. To examine the influence of the bacteria on sperm quality, we incubated the 0.1 OD bacteria with $50 \times 10^{6} \mathrm{ml}^{-1}$ sperm cells, which created a bacteria: sperm ratio of $54: 1$. This ratio was determined to be the lowest concentration of the bacteria that caused a sperm motility decrease after $5 \mathrm{~h}$ of incubation. Moreover, it is a similar infection ratio to that in Reichart et al. (2001). A similar concentration of the bacterium Ureaplasma urealyticum was used in a study by Reichart et al. (2000). After 2 days of bacterial growth, bacterial supernatant was produced by centrifugation and the bacterial suspension was passed through a $0.2 \mu \mathrm{m}$ filter.

Sperm morphology analysis was performed using scanning electron microscopy as described previously (Evenson \& Wixon, 2005).

Parameters of sperm viability. The parameters examined included motility, viability, morphology, sperm chromatin structure and FAS receptor expression, as these have been shown to predict sperm cell damage (Reichart et al., 2000). The motility parameter indicates a tail defect, while all the other parameters are indicative of a head defect.

The mean $\alpha$ t value (an indication of the chromatin stability of the sperm cell) and \%COMP $\alpha$ t (percentage of cells outside the main peak) were assessed by testing 10 aliquots of fixed sperm nuclei by FACS analysis (Reichart et al., 2000).

The sperm were incubated in Ringer's glucose phosphate with $0.5 \%$ glucose at room temperature $\left(25^{\circ} \mathrm{C}\right)$ for the duration of the

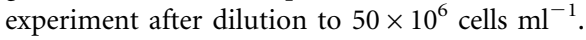

Sperm motility was determined using the sperm quality analyser (SQA; Gameta). The SQA has a photoelectric cell that detects fluctuations in the optical density of the suspension caused by the motility of sperm and converts them to a sperm motility index value (as described by Reichart et al., 2000).

FAS receptor expression. FAS receptor expression was determined by immunofluorescence. Rabbit polyclonal anti-FAS IgG $[2 \mu \mathrm{l}(\mathrm{ml}$ sperm suspension $)^{-1}$ (MACS antibody; Miltent)] was added to each sample, which was then incubated at room temperature for $1.5 \mathrm{~h}$. The samples were then washed and secondary antibody [bovine anti-rabbit IgG FITC, $1 \mu \mathrm{l}$ ( $\mathrm{ml} \mathrm{sample})^{-1}$; Santa Cruz Biotechnology] was added for $30 \mathrm{~min}$ at $37^{\circ} \mathrm{C}$. The labelled cells represented damaged sperm. The cells were analysed by FACS at an excitation wavelength of $488 \mathrm{~nm}$ and emission wavelength of $535 \mathrm{~nm}$ (Xu et al., 2001).
Statistical analysis. All statistical analyses were performed using SPSS for Windows, version 10.0. The sperm samples analysed in this study included spermatozoa incubated with bacteria and untreated sperm cells. Therefore, the type of treatment (bacteria/control) was defined as a between-sample factor. The sperm parameters motility index, percentage of live spermatozoa, mean $\alpha$ t value and percentage of sperm cells with FAS receptor were measured at two time points: $15 \mathrm{~min}$ and $5 \mathrm{~h}$ after the start of the experiment. Fifteen minutes is the minimum time to determine whether the bacterial influence is immediate, and $5 \mathrm{~h}$ reflected a time between capacitation and acrosome reaction of the sperm, as in mammals it is known that the time before fertilization with the oocyte is $4-5 \mathrm{~h}$ (Takahashi et al., 1992). Therefore, the time of evaluation was defined as a withinsample factor. Time changes in the sperm parameters of the treated versus untreated samples were analysed using ANOVA with repeated measures. The between-sample changes in these parameters were analysed by ANOVA and the within-sample changes were analysed using a paired $t$-test. With regard to sperm morphology, one-way ANOVA was used since these variables were assessed only once, after $5 \mathrm{~h}$ of incubation.

\section{RESULTS AND DISCUSSION}

To evaluate the effects of $C$. fetus subsp. fetus on sperm, changes in four parameters indicative of sperm quality and fertility, i.e. motility index, percentage of live spermatozoa, percentage of sperm cells expressing FAS receptor and mean $\alpha$ t value, were examined in the control group of untreated sperm $(\mathrm{C})$ and in samples incubated with C. fetus subsp. fetus bacteria (B) at $15 \mathrm{~min}$ and $5 \mathrm{~h}$. After $5 \mathrm{~h}$ of incubation, these parameters in both the treated and control sperm were significantly lower compared to their mean values at $15 \mathrm{~min}$ (for example, sperm motility index was $524 \pm 21.4$ vs $463 \pm 24.4, t=7.2$, and $519 \pm 16.4$ vs $333 \pm 48.1, \quad t=13.9$, respectively; $P \leqslant 0.01$, Table 1 ). Comparison of control sperm and those incubated with the bacteria revealed that the two groups were statistically similar in their $15 \mathrm{~min}$ motility-index values; however, after $5 \mathrm{~h}$ of incubation, the bacteria-treated samples exhibited significantly lower values of this variable compared to controls $(F=46.9, P \leqslant 0.01$; Table 1$)$.

Similar results were obtained with regard to sperm viability. The percentage of live spermatozoa was significantly

Table 1. Comparison of parameters of sperm quality and fertility in control sperm samples and samples incubated with C. fetus subsp. fetus

\begin{tabular}{|c|c|c|c|c|c|}
\hline \multirow[t]{2}{*}{ Sperm characteristics } & \multirow[t]{2}{*}{ No. of experiments } & \multicolumn{2}{|c|}{ Control: time of incubation (h) } & \multicolumn{2}{|c|}{ With bacteria: time of incubation $(h)$} \\
\hline & & 0.25 & 5 & 0.25 & 5 \\
\hline Motility index & 8 & $523.9 \pm 21.4$ & $463.4 \pm 24.4^{\star}$ & $519.2 \pm 16.4$ & $332.7 \pm 48.1^{\star} \dagger \ddagger$ \\
\hline Viability (\%) & 6 & 85.6. \pm 5.8 & $76.5 \pm 7.2^{*}$ & $82.0 \pm 5.2$ & $62.2 \pm 10.1^{\star} \dagger \ddagger$ \\
\hline FAS $(\%)$ & 6 & $16.8 \pm 4.8$ & $21.0 \pm 5.3$ & $36.2 \pm 7.1 \dagger$ & $61.6 \pm 11.9^{*} \dagger \ddagger$ \\
\hline$\alpha \mathrm{t}$ & 10 & $213.1 \pm 47.5$ & $217.2 \pm 46.9$ & $214.4 \pm 47.0$ & $215.5 \pm 49.7$ \\
\hline
\end{tabular}

${ }^{\star}$ Significantly different from the value at $15 \min (P \leqslant 0.01)$.

$\dagger$ Significantly different from the control value $(P \leqslant 0.01)$.

$\ddagger$ Significant interaction between type of treatment $(C / B)$ and time $(0.25 / 5)$. 
decreased after $5 \mathrm{~h}$ of incubation in both bacteriaincubated and control samples compared to their values after $15 \mathrm{~min}(85.6 . \pm 5.8 \%$ vs $76.5 \pm 7.2 \%, t=12.2$, and $82.0 \pm 5.2 \%$ vs $62.2 \pm 10.1 \%, t=8.0$, respectively, $P \leqslant 0.01$; Table 1).

Both samples exhibited similar sperm viability after $15 \mathrm{~min}$; however, after $5 \mathrm{~h}$ of incubation, the sperm co-incubated with bacteria exhibited significantly lower viability compared to the control $(F=8.0, P \leqslant 0.02$; Table 1$)$.

No change over time was observed in the percentage of control sperm cells expressing the FAS receptor; however, in sperm incubated with the bacteria, the degree of FAS expression after $5 \mathrm{~h}$ of incubation was significantly higher compared with expression after only $15 \mathrm{~min}$ incubation $(61.6 \pm 11.9 \%$ vs $36.2 \pm 7.1 \%, t=-8.1, P \leqslant 0.01$; Table 1$)$.

It is notable that the percentage of bacterially treated sperm cells expressing FAS receptor was already significantly higher than in the controls after $15 \min (36.2 \pm 7.1 \%$ vs $16.8 \pm 4.8 \%, F=30.7, P \leqslant 0.01)$. A similar increase in FAS expression was observed after $5 \mathrm{~h}$ of incubation $[61.6 \pm 11.9 \%$ (+ bacteria) vs $21.0 \pm 5.3 \%$ (control), $F=$ 58.1, $P \leqslant 0.01$; Table 1]. No significant changes within or between samples were observed with regard to the $\alpha$ t values (Table 1).

Of the five sperm morphological defects examined after $5 \mathrm{~h}$ of incubation with or without bacteria, i.e. percentages of abnormal acrosome, disconnected heads, agglutinated heads, broken tails and twisted tails, four of these occurred at a significantly higher prevalence in the samples incubated with bacteria (abnormal acrosome: $23.4 \pm 8.8 \%$ vs $14.3 \pm 5.8 \%, t=-6.4$; disconnected heads: $28.1 \pm 9.8 \%$ vs $16.7 \pm 4.1 \%, t=-4.2$; agglutinated heads: $40.6 \pm 10.7 \%$ vs $22.5 \pm 7.0 \%, t=-7.0, P \leqslant 0.01$; and broken tails: $25.6 \pm 10.2 \%$ vs $14.6 \pm 7.8, t=-3.0, P \leqslant 0.03$; Table 2 ). The percentage of twisted tails was not statistically different between groups (Table 2; Fig. 1).

To determine whether the bacteria act through a secreted factor, changes over time in motility index, percentage of live spermatozoa, percentage of sperm cells with FAS receptor and mean $\alpha$ t values were examined in the control sperm samples and compared to those in sperm samples incubated with the supernatant of C. fetus subsp. fetus cultures. As above, in both treated and control groups, the motility index was significantly decreased after $5 \mathrm{~h}$ of incubation compared to the initial state $(518.7 \pm 12.8$ vs $442.6 \pm 31.3, t=8.6$; and $367.3 \pm 45.3$ vs $131.2 \pm 45.3$, $t=17.0$, respectively, $P \leqslant 0.01$; Table 3 ). Comparison of supernatant and control groups demonstrated that at both time points, $15 \mathrm{~min}$ and $5 \mathrm{~h}$, the mean motility index in the treated sperm was significantly lower compared to that in the control $(F=123.7$ and $F=383.3$, respectively, $P$ $\leqslant 0.01$; Table 3 ). In both groups, the percentage of live spermatozoa was significantly decreased after $5 \mathrm{~h}$ of incubation compared to the $15 \mathrm{~min}$ time point $(84.2 \pm 9.0 \% \quad$ vs $72.6 \pm 8.6 \%, \quad t=2.9, \quad P \leqslant 0.04$; and $76.2 \pm 11.3 \%$ vs $40.2 \pm 4.5 \%, t=7.6, P \leqslant 0.01$, respectively; Table 3).

There was no significant difference at 15 min between the sperm samples in their sperm viability values; however, after $5 \mathrm{~h}$ of incubation, sperm viability in the supernatantincubated samples was significantly lower compared to that in the controls $(F=102.0, P \leqslant 0.01$; Table 3$)$.

As above, no significant changes over time were observed for FAS receptor expression in the control group; however, for sperm treated with bacterial supernatant, the mean value of this parameter after $5 \mathrm{~h}$ of incubation was significantly higher compared to that at $15 \mathrm{~min}$ $(94.0 \pm 3.1 \%$ vs $83.7 \pm 2.6 \%, t=-12.8, P \leqslant 0.01$; Table $3)$. At both points tested ( $15 \mathrm{~min}$ and $5 \mathrm{~h}$ ), the percentage of sperm cells expressing FAS receptor in supernatanttreated cultures was significantly higher compared with the control $(83.7 \pm 2.6 \%$ vs $14.0 \pm 2.4 \%$; and $94.0 \pm 3.1 \%$ vs $17.7 \pm 6.3 \%$, respectively, $F=2674.5$ and $F=779.0$, respectively, $P \leqslant 0.01)$. No significant changes were observed for the mean $\alpha$ t values.

After $1 \mathrm{~h}$ of incubation in bacterial supernatant, all five morphological defects studied occurred at a significantly higher prevalence in samples treated with bacterial supernatant relative to the control (Table 4) $(t=-5.8$, $t=-6.2, \quad t=-7.3, \quad t=-4.3$ and $t=6.9$, respectively, $P$ $\leqslant 0.03$; Table 4).

To determine whether the effect of C. fetus subsp. fetus on the sperm cells is unique to this bacterial species, we compared its effects to those of other Gram-negative bacteria, E. coli, commonly found in the natural flora of the intestine, and Erwinia amylovora, which exists on growing plants. While $C$. fetus subsp. fetus had a significant effect on motility $(P \leqslant 0.01)$, viability $(P \leqslant 0.05)$ and FAS

Table 2. Comparison of different morphological malformations in control sperm samples and samples incubated with $C$. fetus subsp. fetus, after $5 \mathrm{~h}$

Values are the percentage of sperm exhibiting malformation. Seven experiments were performed, with 100 sperm analysed in each experiment.

\begin{tabular}{|lccccc|}
\hline Sperm samples & Abnormal acrosome & Disconnected heads & Agglutinated heads & Broken tails & Twisted tails \\
\hline C. fetus subsp. fetus & $23.4 \pm 8.8^{\star}$ & $28.1 \pm 9.8^{*}$ & $40.6 \pm 10.7^{\star}$ & $25.6 \pm 10.2^{\star}$ & $18.6 \pm 6.8$ \\
Control & $14.3 \pm 5.8$ & $16.7 \pm 4.1$ & $22.5 \pm 7.0$ & $14.6 \pm 7.8$ & $17.6 \pm 6.4$ \\
\hline
\end{tabular}

* Significantly different from the control value $(P \leqslant 0.01)$. 
(a)

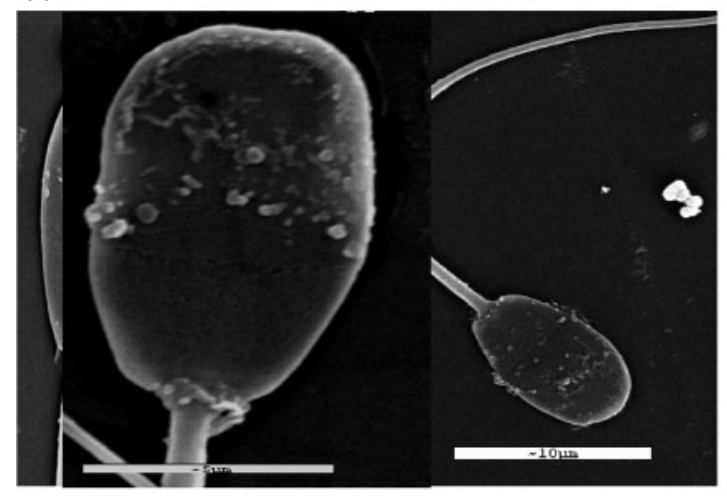

(b)
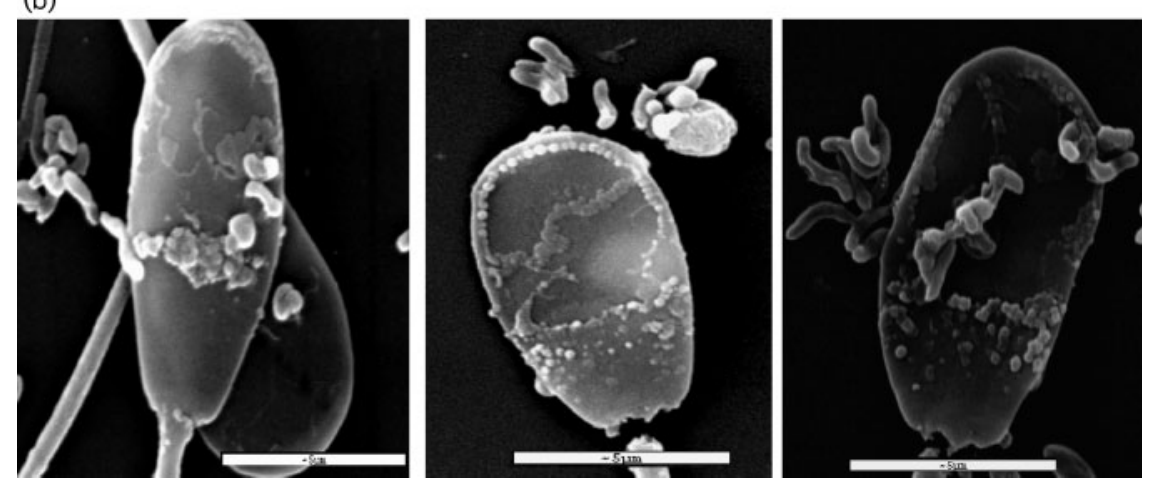

Fig. 1. (a) Scanning electron micrograph of non-infected sperm (in Ringer's glucose phosphate, pH 6.3) (control); (b) scanning electron micrograph of bacteria-infected sperm cells (with C. fetus subsp. fetus, 1:54 ratio of sperm cell to bacterial cells, in Ringer's glucose phosphate, $\mathrm{pH}$ 6.3). Bar, $5 \mu \mathrm{m}$. The figure shows different types of damage to the sperm cell mediated by the bacteria, including cut-off head, damage to the acrosome, and cells in various stages of apoptosis.

expression $(P \leqslant 0.05)$, no significant effect was induced by the other bacterial species (Table 5 ). This shows that $C$. fetus subsp. fetus has a unique effect on ram sperm quality.

Over recent decades, the phenomenon of infertility and early abortion in sheep with a background of $C$. fetus subsp. fetus infection in the female tract has become known
(Agerholm et al., 2006). Brooks et al. (2001) have examined the effect of $C$. fetus subsp. fetus on the female genital tract. The present study focused on the possible contribution of the bacteria to subfertility mediated by male factors. Our results suggest that the occurrence of subfertility in sheep may also be related to the presence of the bacteria in the semen, in agreement with Eaglesome et al. (1995). We have

Table 3. Comparison of parameters of sperm quality and fertility for control sperm samples and samples incubated with $C$. fetus subsp. fetus supernatant

\begin{tabular}{|c|c|c|c|c|c|}
\hline \multirow[t]{2}{*}{ Sperm characteristics } & \multirow[t]{2}{*}{ No. of samples } & \multicolumn{2}{|c|}{ Control: time of incubation (h) } & \multicolumn{2}{|c|}{$\begin{array}{l}\text { With bacterial supernatant: time of incubation } \\
\text { (h) }\end{array}$} \\
\hline & & 0.25 & 5 & 0.25 & 5 \\
\hline Motility index & 12 & $518.7 \pm 12.8$ & $442.6 \pm 31.3^{*}$ & $367.3 \pm 45.3 \dagger$ & $131.2 \pm 45.3^{*} \dagger \neq$ \\
\hline Viability (\%) & 5 & $84.2 \pm 9.0$ & $72.6 \pm 8.6^{*}$ & $76.2 \pm 11.3$ & $40.2 \pm 4.5^{\star} \dagger \neq$ \\
\hline FAS (\%) & 7 & $14.0 \pm 2.4$ & $17.7 \pm 6.3$ & $83.7 \pm 2.6 \dagger$ & $94.0 \pm 3.1^{\star} \dagger \neq$ \\
\hline$\alpha \mathrm{t}$ & 12 & $203.5 \pm 48.4$ & $204.7 \pm 48.2$ & $221.3 \pm 39.3$ & $228.0 \pm 41.1$ \\
\hline
\end{tabular}

${ }^{\star}$ Significantly different from the value at $15 \min (P \leqslant 0.01)$.

$\dagger$ Significantly different from the control value $(P \leqslant 0.01)$.

$\ddagger$ Significant interaction between type of treatment $(C / B)$ and time changes $(0.25 / 5)$ in the variable. 
Table 4. Comparison of morphological malformations of control sperm samples and samples incubated for $1 \mathrm{~h}$ with $\mathrm{C}$. fetus subsp. fetus supernatant

Values are the percentage of sperm exhibiting malformation.

\begin{tabular}{|lccccc|}
\hline Sperm samples & Abnormal acrosome & Disconnected heads & Agglutinated heads & Broken tails & Twisted tails \\
\hline Incubated with supernatant & $28.8 \pm 9.8^{*}$ & $36.8 \pm 10.6^{*}$ & $34.2 \pm 8.7^{*}$ & $24.7 \pm 7.3^{*}$ & $24.7 \pm 6.9^{*}$ \\
Control & $12.3 \pm 3.2$ & $14.5 \pm 2.7$ & $22.2 \pm 7.9$ & $17.3 \pm 6.1$ & $15.0 \pm 5.2$ \\
\hline
\end{tabular}

${ }^{\star}$ Significantly different from the control value $(P \leqslant 0.01)$.

shown the occurrence of characteristics previously related to sperm subfertility induced by the infection of sperm with C. fetus subsp. fetus. Following exposure to the bacteria, sperm cells introduced into the female (even by artificial insemination) can lose their viability and motility, thus reducing fertility potential and the chance of the semen to fertilize (Berkovitz et al., 2004).

Bacterial infection may cause occlusion of the male tract or the accessory glands and thus lead to a decrease in the amount of sperm cells. It may even be related to a decrease in the quality of the sperm cells secreted into the semen, as expressed by a decrease in sperm cell motility and an increase in the number of sperm cells exhibiting abnormal morphology (Diemer et al., 1996).

Vizzier-Thaxton et al. (2006) reported that horizontal and vertical transmission of Salmonella and Campylobacter can occur in broiler breeder flocks. Although the mechanism of this transmission is still unclear, scanning electron microscopy showed that Salmonella was associated with all three segments (head, midpiece and tail) of the spermatozoa and was, apparently, equally distributed. Campylobacter was mainly associated with the midpiece and tail segments; few isolates were located on the head segment (Vizzier-Thaxton et al., 2006). In this study, we found that $C$. fetus subsp. fetus was attached to two main regions: the tail (close to the mitochondrial area) and the acrosome, especially the post-acrosome region (Fig. 1). The damage to sperm was manifested in characteristics associated with both the motility and chromatin regions. Bacteria-infected sperm cells showed a decrease in motility and an increase in premature acrosome reaction as well as chromatin damage. C. fetus subsp. fetus caused the sperm head to separate from the tail, a significant increase in the development of apoptosis, and acrosome damage (Fig. 1).

Sperm morphology is considered disturbed in the presence of more than $20 \%$ abnormal sperm cells (Liu et al., 2004). Incubation (up to $5 \mathrm{~h}$ ) of sperm cells with C. fetus subsp. fetus caused up to $30 \%$ of cut-off heads, early acrosome reaction and agglutination. Recent reports show that the presence of bacteria in semen may lead to early abortions as a result of damage to sperm cells (Reichart et al., 2000). Thus the bacteria can cause damage to sperm that will only be manifested following fertilization. This could explain why the bacteria have been recognized more as a trigger of abortion than a reason for infertility (Agerholm et al., 2006).

The nature of the agent secreted by C. fetus subsp. fetus causing toxicity to sperm is not known. LPS has been suggested as mediating the toxic effects of the bacterium (Brooks et al., 2002). Kajihara et al. (2006) found that LPStreated mice demonstrate an increase in FAS-positive cells in many germ cell populations, especially in spermatocytes and spermatids. Their study suggests that the Fas/FasL system mediates apoptosis of germ cells in the testis of LPS-

Table 5. Comparison of parameters of sperm quality in samples incubated with C. fetus subsp. fetus versus Erwinia amylovora or E. coli

\begin{tabular}{|c|c|c|c|c|c|c|c|c|c|}
\hline \multirow{2}{*}{$\begin{array}{l}\text { Sperm char- } \\
\text { acteristics }\end{array}$} & \multirow{2}{*}{$\begin{array}{c}\text { No. of } \\
\text { experiments }\end{array}$} & \multicolumn{4}{|c|}{ Time of incubation $(0.25 \mathrm{~h})$} & \multicolumn{4}{|c|}{ Time of incubation (5 h) } \\
\hline & & Control & C. fetus & $\begin{array}{c}\text { Erwinia } \\
\text { amylovora }\end{array}$ & E. coli & Control & C. fetus & $\begin{array}{c}\text { Erwinia } \\
\text { amylovora }\end{array}$ & E. coli \\
\hline Motility index & 5 & $523.9 \pm 21.4$ & $519.2 \pm 16.4$ & $531.7 \pm 73.4$ & $518.9 \pm 94.3$ & $463.4 \pm 24.4$ & $332.7 \pm 48.1 \dagger$ & $445.71 \pm 46.4 \ddagger$ & $396.5 \pm 33.6 \dagger$ \\
\hline Viability (\%) & 5 & 85.6. \pm 5.3 & $76.5 \pm 7.2$ & $86.2 \pm 5.8$ & $83.7 \pm 8.4$ & $76.5 \pm 7.2$ & $62.2 \pm 10.1^{\star}$ & $78.4 \pm 8.5 \ddagger$ & $73.6 \pm 2.1 \dagger$ \\
\hline
\end{tabular}

*Significantly different from the control $(P \leqslant 0.05)$. $\dagger$ Significantly different from the control $(P \leqslant 0.01)$.

¥No significant difference from the control. 
treated mice (Kajihara et al., 2006). Nevertheless, it has been shown that different species of bacteria produce LPS with different structures and toxicity (Braun et al., 2005). The synthesis of toxic LPS is regulated by environmental and nutritional factors (such as sugar). C. fetus subsp. fetus demonstrates significantly greater toxicity than other bacteria such as Erwinia amylovora and E. coli. It is possible that this difference reflects the production by $C$. fetus subsp. fetus of higher levels of toxic LPS than other bacteria.

This study provides an important basis for understanding the mechanism of bacterial effects on the male and female genital tracts by showing that C. fetus subsp. fetus can be toxic to the sperm cells.

\section{REFERENCES}

Agerholm, J. S., Aalbaek, B., Fog-Larsen, A. M., Boye, M., Holm, E., Jensen, T. K., Lindhardt, T., Larsen, L. E. \& Buxton, D. (2006). Veterinary and medical aspects of abortion in Danish sheep. APMIS 114, 146-152.

Berkovitz, A., Eltes, F., Yaari, S., Katz, N., Barr, I., Fishman, A. \& Bartoov, B. (2004). The morphological normalcy of the sperm nucleus and pregnancy rate of intracytoplasmic injection with morphologically selected sperm. Hum Reprod 20, 185-190.

Braun, S. G., Meyer, A., Holst, O., Pühler, A. \& Niehaus, K. (2005). Characterization of the Xanthomonas campestris pv. campestris lipopolysaccharide substructures essential for elicitation of an oxidative burst in tobacco cells. Mol Plant Microbe Interact 18, 674-681.

Brooks, B. W., Robertson, R. H., Lutze-Wallace, C. L. \& Pfahler, W. (2001). Identification, characterization, and variation in expression of two serologically distinct $\mathrm{O}$-antigen epitopes in lipopolysaccharides of Campylobacter fetus serotype A strains. Infect Immun 69, 7596-7602.

Brooks, B. W., Robertson, R. H., Lutze-Wallace, C. L. \& Pfahler, W. (2002). Monoclonal antibodies specific for Campylobacter fetus lipopolysaccharides. Vet Microbiol 87, 37-49.

Diemer, T., Weidner, W., Michelmann, H. W., Schiefer, H. G., Rovan, E. \& Mayer, F. (1996). Influence of Escherichia coli on motility parameters of human spermatozoa in vitro. Int J Androl 19, 271-277.

Eaglesome, M. D., Sampath, M. I. \& Garcia, M. M. (1995). A detection assay for Campylobacter fetus in bovine semen by restriction analysis of PCR amplified DNA. Vet Res Commun 19, 253-263.

Evenson, D. P. \& Wixon, R. (2005). Comparison of the Halosperm test kit with the sperm chromatin structure assay (SCSA) infertility test in relation to patient diagnosis and prognosis. Fertil Steril 84, 846-849.

Garcia, M. M., Ruckerbauer, G. M., Eaglesome, M. D. \& Boisclair, W. E. (1983). Detection of Campylobacter fetus in artificial insemination bulls with a transport enrichment medium. Can J Comp Med 47, 336-340.
Grogono-Thomas, R., Dworkin, J., Blaser, M. J. \& Newell, D. G. (2000). Roles of the surface layer proteins of Campylobacter fetus subsp. fetus in ovine abortion. Infect Immun 68, 1687-1691.

Hood, M. \& Todd, J. M. (1960). Vibrio fetus - a cause of human abortion. Am J Obstet Gynecol 80, 506-511.

Kajihara, T., Okagaki, R. \& Ishihara, O. (2006). LPS-induced transient testicular dysfunction accompanied by apoptosis of testicular germ cells in mice. Med Mol Morphol 39, 203-208.

Lancaster, C. R. \& Simon, J. (2002). Succinate:quinone oxidoreductases from epsilon-proteobacteria. Biochim Biophys Acta 1553, 84-101.

Liu, D. Y., Garrett, C. \& Baker, H. W. (2004). Clinical application of sperm-oocyte interaction tests in in vitro fertilization - embryo transfer and intracytoplasmic sperm injection programs. Fertil Steril 82, 1251-1263.

Mannering, S. A., West, D. M., Fenwick, S. G., Marchant, R. M. \& O'Connell, K. (2006). Pulsed-field gel electrophoresis of Campylobacter jejuni sheep abortion isolates. Vet Microbiol 115, 237-242.

Penner, J. L. (1988). The genus Campylobacter: a decade of progress. Clin Microbiol Rev 1, 157-172.

Reichart, M., Kahane, I. \& Bartoov, B. (2000). In vivo and in vitro impairment of human and ram sperm nuclear chromatin integrity by sexually transmitted Ureaplasma urealyticum infection. Biol Reprod 63, 1041-1048.

Reichart, M., Bartoov, B., Levi, H. \& Kahane, I. (2001). Dual energy metabolism-dependent effect of Ureaplasma urealyticum infection on sperm activity. J Androl 22, 404-412.

Schulze, F., Bagon, A., Muller, W. \& Hotzel, H. (2006). Identification of Campylobacter fetus subspecies by phenotypic differentiation and PCR. J Clin Microbiol 44, 2019-2024.

Steinkraus, G. E. \& Wright, B. D. (1994). Septic abortion with intact fetal membranes caused by Campylobacter fetus subsp. fetus. J Clin Microbiol 32, 1608-1609.

Takahashi, K., Wetzels, A. M., Goverde, H. J., Bastaans, B. A., Janssen, H. J. \& Rolland, R. (1992). The kinetics of the acrosome reaction of human spermatozoa and its correlation with in vitro fertilization. Fertil Steril 57, 889-894.

van Bergen, M. A., van der Graaf-van Bloois, L., Visser, I. J., van Putten, J. P. \& Wagenaar, J. A. (2006). Molecular epidemiology of Campylobacter fetus subsp. fetus on bovine artificial insemination stations using pulsed field gel electrophoresis. Vet Microbiol 112, 65-71.

Vizzier-Thaxton, Y., Cox, N. A., Richardson, L. J., Buhr, R. J., McDaniel, C. D., Cosby, D. E., Wilson, J. L., Bourassa, D. V. \& Ard, M. B. (2006). Apparent attachment of Campylobacter and Salmonella to broiler breeder rooster spermatozoa. Poult Sci 85, 619-624.

Xu, C., Lu, M. G., Feng, J. S., Guo, Q. S. \& Wang, Y. F. (2001). Germ cell apoptosis induced by Ureaplasma urealyticum infection. Asian $J$ Androl 3, 199-204. 